\title{
Simulation of Femur Bone Fracture in Car Accident using CT Scan Data and Finite Element Analysis
}

\author{
A. Chennakesava Reddy ${ }^{1}$, B. Kotiveerchari ${ }^{2}$ \\ ${ }^{1}$ Professor, Department of Mechanical Engineering, JNTUH College of Engineering, Kukatpally, Hyderabad - 500 085, Telangana, India \\ ${ }^{2}$ Professor, Department of Mechanical Engineering, National Institute of Technology, Warangal, Telangana, India
}

\begin{abstract}
Fracture of femur bones in car accident is common. In the present work, the fracture of femur bone was modeled as a failure under three-point bending. The CT scan data was converted into 3D solid modeling using Mimics software. The finite element analysis (FEA) was carried out using ANSYS software. The FEA results were in good agreement with the experiment results.
\end{abstract}

Keywords: Femur bone, CT scan data, Mimics, ANSYS, Finite Element Analysis.

\section{Introduction}

Bone is a functionally graded material, composed by hydroxyapatite, collagen, traces of proteoglycans, noncollagenous proteins and water [1]. The femur (figure 1) is the longest and by most measures, the strongest bone in the human body. Its length on average is $26.74 \%$ of a person's height [2]. The neck is $40-50 \mathrm{~mm}$ long and the diameter is smallest front to back and compressed at its middle. The column forms an angle with the shaft in about $130^{\circ}$. This angle is highly variable. In the infant it is about $150^{\circ}$ and in old age reduced to $120^{\circ}$ on average. The femur is the most proximal bone of the leg in tetrapod vertebrates capable of walking or jumping.

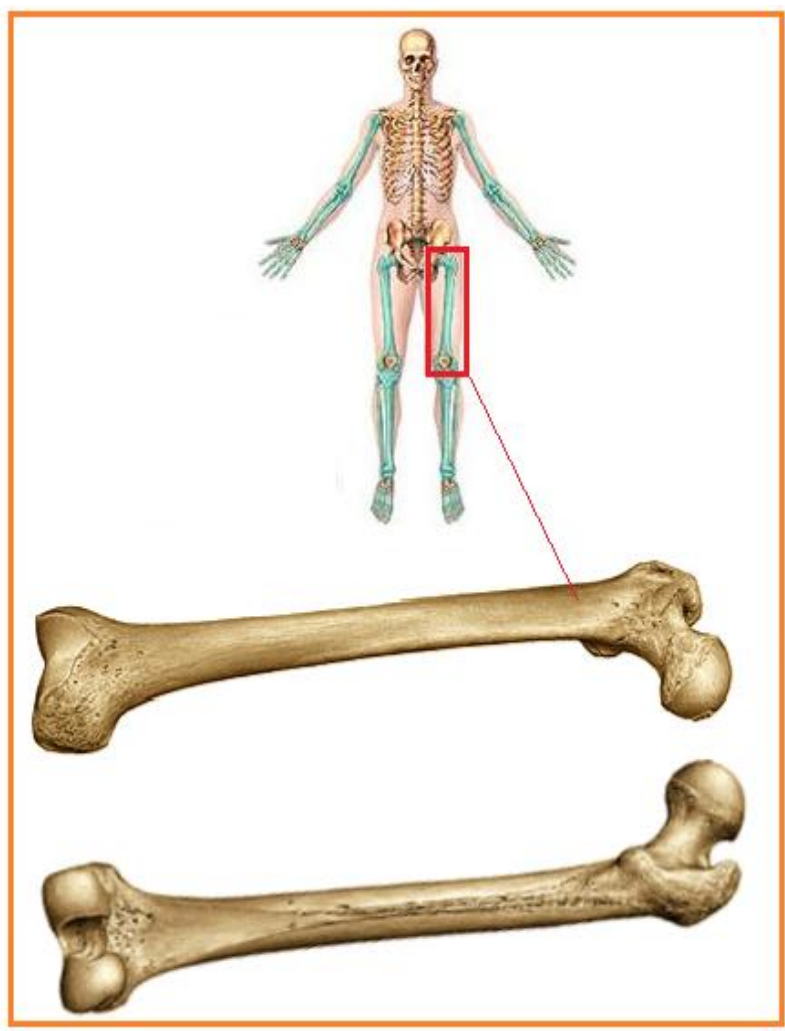

Figure 1: The femur bone.

The femur is a tremendously strong bone. For a femur fracture to occur either a large force must be applied or some- thing is wrong with the bone. In patients with normal bone strength, the most common causes of femur fractures include car accidents or fall from a height. The fractured femur bone in car accident is shown in figure 2. The shaft of the femur is cylindrical with approximately circular cross section shape and is found to possess a longitudinal bone eccentricity or shape eccentricity.

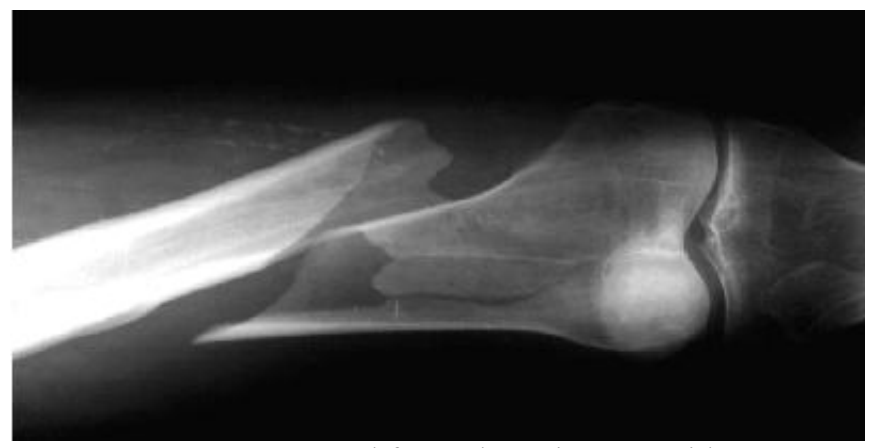

Figure 2: Fractured femur bone in car accident.

For a given load bending generates much higher stresses in the bones than pure axial compression, since in bending the external surface is subjected to high stresses [3]. As a result, the bones that are subjected to bending have lower mechanical strengths than the bones subjected to pure axial compression. The proximal femur is stressed by two resultant forces, $\mathrm{R}_{\mathrm{h}}$ and $\mathrm{R}_{\mathrm{t}}$. The trochanteric resultant force $\mathrm{R}_{\mathrm{t}}$ is the vectorial sum of the muscle resultant force $F_{m t}$ exerted by all the abductor muscles and the force $F_{m k}$ [4]. In order to properly simulate the loading condition of the bone, knowledge of the biomechanics involved is required. There are three loading conditions usually considered in finite element (FE) analysis of the femur. These loading conditions are similar to the anatomical loading in the actual femur. They are: Static onelegged stance, Gait loading, Impact loading, or loading during fall. Bone density, mechanical properties and geometry are the main contributors to bone strength. Until date, there is no alternative to experimental mechanical testing to account for all these parameters when determining bone failure loads. Finite element models combined with computed tomography (CT) imaging seem to provide accurate estimations of bone strength [5]. Finite element analysis (FEA) continues to be useful since it can replicate osteoporotic conditions in a FE 


\section{International Journal of Science and Research (IJSR) \\ ISSN (Online): 2319-7064 \\ Index Copernicus Value (2013): 6.14 | Impact Factor (2013): 4.438}

model and have the ability to iterate many types of load cases in one study [6].

In the present work, fracture behavior of femur bone subjected to bending load was investigated. The results obtained from FEA were verified with experimental results.

\section{Materials and Methods}

The femur bone tested under three-point bending using universal testing machine as shown in figure 3 .

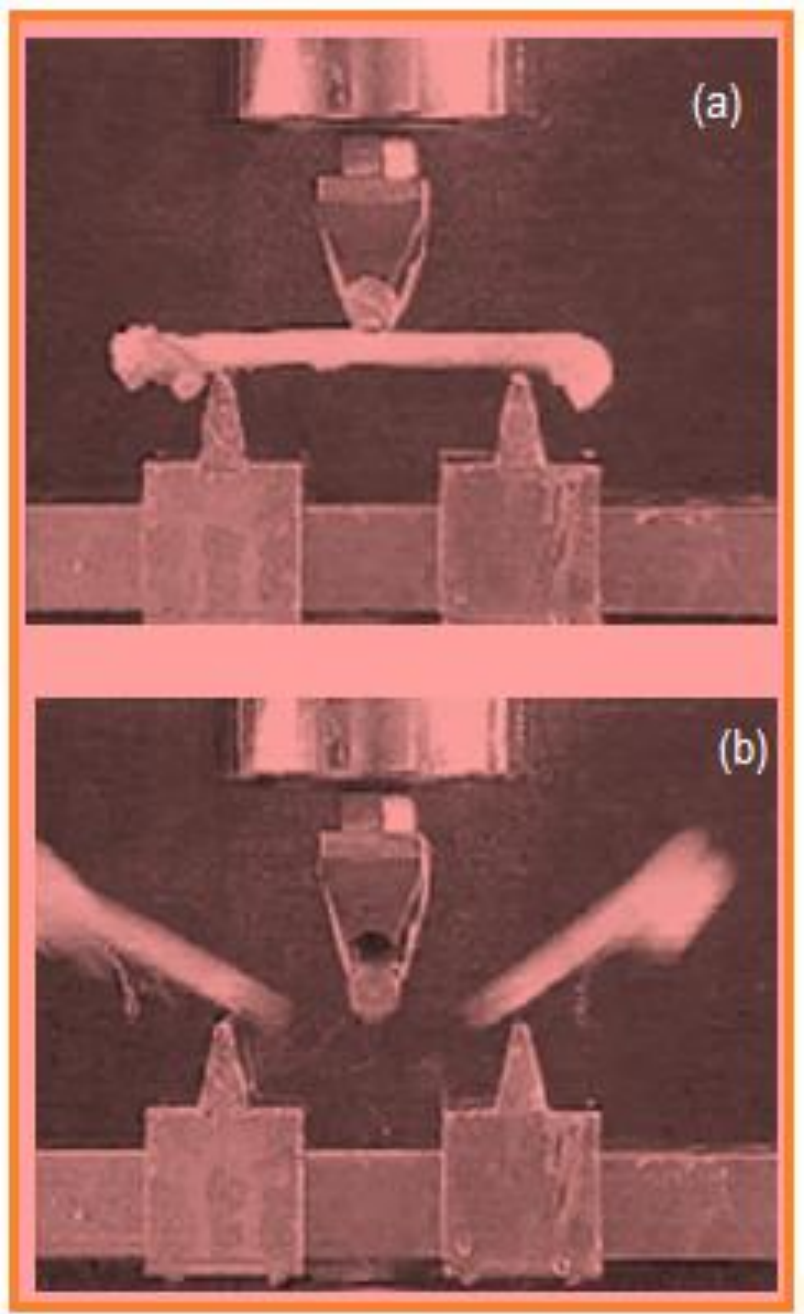

Figure 3: Three-point bending test of femur bone: (a) before test and (b) after test.

The bending stress at a point in a beam section was calculated using the formula: $\sigma=\mathrm{My} / \mathrm{I}$, where $\mathrm{M}$ is the bending moment, $y$ is the perpendicular distance from the neutral axis to the point of interest (strain gauge location), and $\mathrm{I}$ is the second moment of area of the section of interest. Then, strains were calculated from these values by dividing the elastic modulus obtained by FEA.

The 3D solid model of the femur used in the present was generated using Mimics software with CT scan data (table 1). The $3 \mathrm{~d}$ solid model was imported to ANSYS software for the finite element analysis. The femur bone was meshed with 4-noded tetrahedral solid elements. This element is well suited to model irregular meshes [7]. The element is defined by four nodes having six degrees of freedom at each node: translations in the nodal $\mathrm{x}, \mathrm{y}$, and $\mathrm{z}$ directions and rotations about the nodal $\mathrm{x}, \mathrm{y}$, and $\mathrm{z}$ directions (figure 4). The element also has stress stiffening capability. Beside the nodes, the element input data includes the orthotropic material properties. Orthotropic material directions correspond to the element coordinate directions. Pressures may be input as surface loads on the element faces as shown by the circled numbers on figure 4. Positive pressures act into the element. The element also has stress stiffening capability. Each model consisted of 75000 nodes and 300000 elements (figure 5).

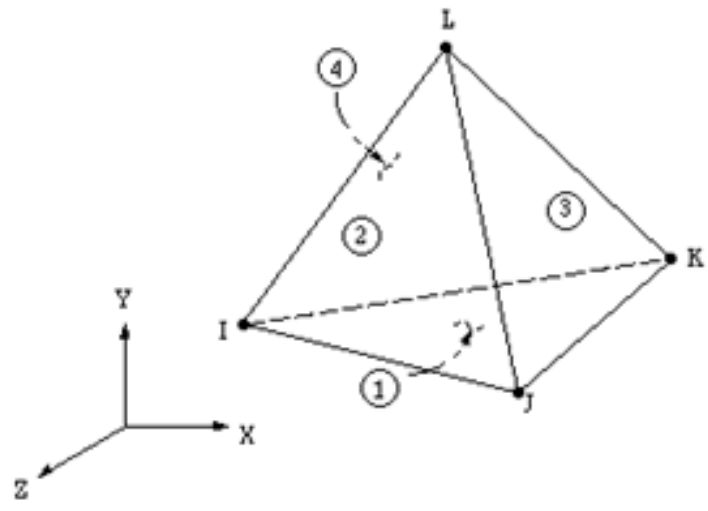

Figure 4: The 4-noded tetrahedral solid element.

Table 1: Dimensions of CT scanned femur data

\begin{tabular}{|l|l|l|}
\hline S.No. & Dimension & Value, $\mathrm{mm}$ \\
\hline 1 & Length & 427.24 \\
\hline 2 & Radius & 13.62 \\
\hline 3 & Shape eccentricity & 18.39 \\
\hline 4 & Load eccentricity & 30.96 \\
\hline 5 & Radius of curvature & 754.78 \\
\hline
\end{tabular}

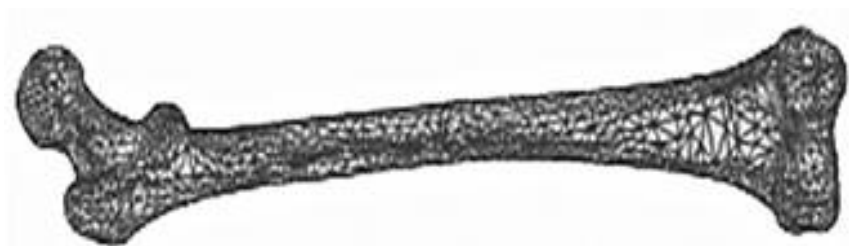

Figure 5: Finite modeling of femur bone

\section{Results and Discussion}

The stress distribution in the femur bone is shown in figure 6. The allowable bending force was $115.6 \mathrm{~N}$ in three-point testing. Lateral unintended impacts to feet, such as those which occur in car accidents, usually cause 3-point bending. The displacement distribution in the femur bone is shown in figure 7 . The maximum deflection of the femur bone was $0.284 \mathrm{E}-06 \mathrm{~mm}$. The experimental deflection was $8 \%$ lower than that obtained from FEA results. The elastic modulus of the femur bone was $1.68 \mathrm{GPa}$. An irregularity (for example a perforation) bends the stress flows, compacting the streamlines in the locations where abrupt change in the path of streamlines occurs As the dimension of a perforation in the direction perpendicular to the streamlines becomes larger, more abrupt change in the stress flow happens leading to larger stress concentration values. 


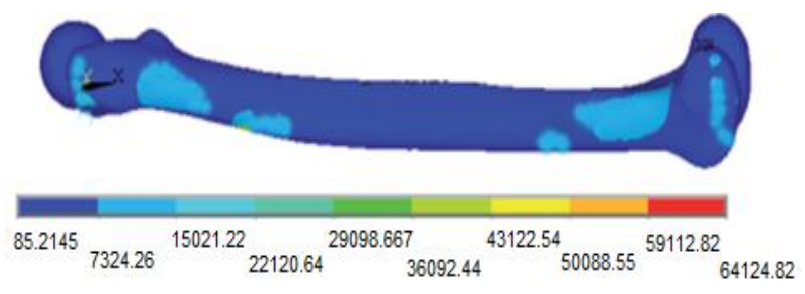

Figure 6: Stress distribution in the femur bone.

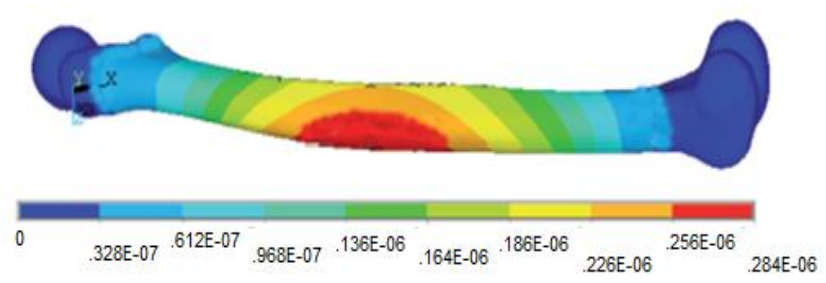

Figure 7: Deflection distribution in the femur bone.

\section{Conclusions}

The tree-point bending test simulates the lateral unintended impacts such as those which occur in car accidents. The FEA results were in good agreement with the experimental results. Therefore, finite element analysis can be extended to investigate the bone fracture such as femur bone.

\section{References}

[1] S. Weiner, and H. D. Wagner, "The material bone: structure mechanical function relations," Annual Review of Materials Science, vol. 28, pp. 271- 298, 1998.

[2] Feldesman, M.R., J.G. Kleckner, and J.K. Lundy, "The femur/stature ratio and estimates of stature in mid-and late-pleistocene fossil hominids.". American Journal of Physical Anthropology, vol. 83 (3), pp.359-372, 1990.

[3] J.E.A. Bertram, A.A. Biewener, "Bone curvature: Sacrificing strength for load predictability," Journal of Theoretical Biology, vol.131, pp.75-92, 1988.

[4] T.P.M. Heimkes, "Function-Orientated Structural Analysis of the Proximal Human Femur,: Cell Tissues Organs, vol.190, pp.247-255, 2009.

[5] J. H. Keyak, and Y. Falkinstein, "Comparison of in situ and in vitro CT scans-based finite element model prediction of proximal femoral fracture load," Medical Engineering \& Physics, vol. 25, pp. 781-787, 2003.

[6] J.H.Keyak and H.B.Skinner, "Three-dimensional finite element modeling of bone: effects of element size," Journal of Biomedical engineering, Vol.14, pp.483-489, 1992.

[7] Chennakesava R Alavala, "Finite Element Methods: Basic Concepts and Applications," PHI Learning Pvt. Ltd, New Delhi, 2008. 